
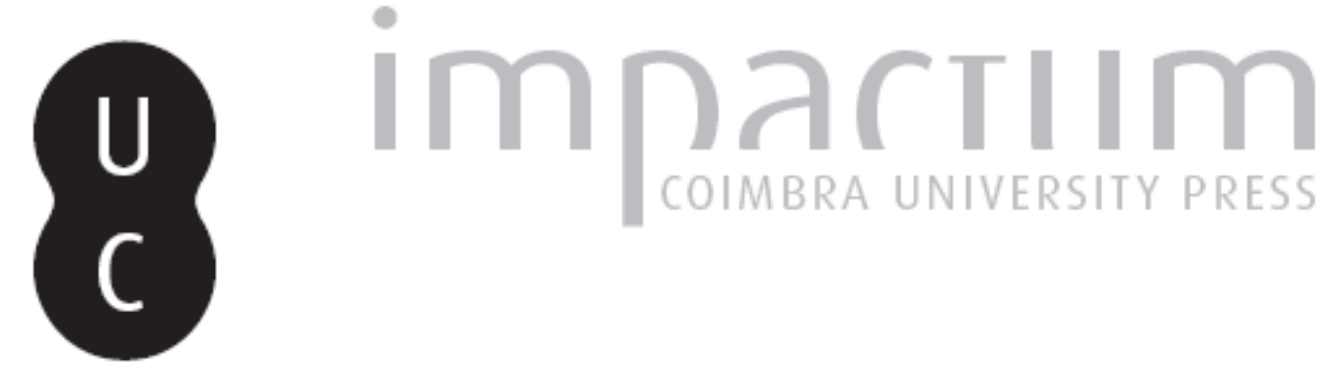

\title{
Percepção de risco a partir do programa defesa civil na escola em Blumenau
}
Autor(es):
Oliveira, Fernanda Ribas de; Ouriques, Juliana Mary de Azevedo;
Correia, Luciana Schramm

Publicado por: Imprensa da Universidade de Coimbra

URL

persistente:

URI:http://hdl.handle.net/10316.2/44194

DOI:

DOI:https://doi.org/10.14195/1647-7723_25-2_7

Accessed : $\quad$ 26-Apr-2023 14:34:06

A navegação consulta e descarregamento dos títulos inseridos nas Bibliotecas Digitais UC Digitalis, UC Pombalina e UC Impactum, pressupõem a aceitação plena e sem reservas dos Termos e Condições de Uso destas Bibliotecas Digitais, disponíveis em https://digitalis.uc.pt/pt-pt/termos.

Conforme exposto nos referidos Termos e Condições de Uso, o descarregamento de títulos de acesso restrito requer uma licença válida de autorização devendo o utilizador aceder ao(s) documento(s) a partir de um endereço de IP da instituição detentora da supramencionada licença.

Ao utilizador é apenas permitido o descarregamento para uso pessoal, pelo que o emprego do(s) título(s) descarregado(s) para outro fim, designadamente comercial, carece de autorização do respetivo autor ou editor da obra.

Na medida em que todas as obras da UC Digitalis se encontram protegidas pelo Código do Direito de Autor e Direitos Conexos e demais legislação aplicável, toda a cópia, parcial ou total, deste documento, nos casos em que é legalmente admitida, deverá conter ou fazer-se acompanhar por este aviso.

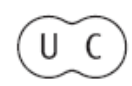




\section{PERCEPÇÃO DE RISCO A PARTIR DO PROGRAMA DEFESA CIVIL NA ESCOLA EM BLUMENAU*}

RISK PERCEPTION FROM THE SCHOOL CIVIL DEFENSE PROGRAM IN BLUMENAU

Fernanda Ribas de Oliveira

Universidade Federal de Santa Catarina (Brasil) ORCID 0000-0002-5461-9402 fernandaribasoliveira@hotmail.com

Juliana Mary de Azevedo Ouriques

Universidade Federal de Santa Catarina (Brasil) ORCID 0000-0001-7082-2454 julimaryouriques@gmail.com

Luciana Schramm Correia

Diretoria de Defesa Civil de Blumenau (Brasil) 0000-0001-7117-2983 lucianacorreia@blumenau.gov.br

\section{RESUMO}

Nacionalmente conhecida pelo histórico de inundações e deslizamentos, Blumenau, localizada no Vale do Itajaí, em Santa Catarina, Brasil, registrou desde a sua fundação, em 1850, 92 inundações, além dos movimentos de massa que atingem todas as regiões do município. Diante de sucessivos registos que ocasionaram danos materiais e perdas humanas, foi necessário estruturar as ações de prevenção, preparação, resposta e reconstrução do município. Uma das ações de prevenção desenvolvidas pelo órgão municipal em parceria com as escolas é o Programa Defesa Civil na Escola, cujo objetivo é tornar as comunidades mais seguras a partir de aulas sobre prevenção de desastres decorrentes de impactos de fenômenos naturais com crianças e adolescentes. 0 presente trabalho propõe-se a analisar a percepção de risco desses alunos por meio da observação participante e pesquisa bibliográfica e documental. Constata-se neste artigo que a percepção de risco torna os alunos capazes de ações e comportamentos de prevenção e resiliência.

Palavras-chave: Percepção de risco, educação, prevenção, desastres naturais, gestão de risco de desastres.

\section{ABSTRACT}

Nationally known for its history of floods and landslides, since its foundation in 1850 Blumenau, in Vale do Itajaí, Santa Catarina, Brazil, has recorded 92 floods as well as mass movements, which have affected all regions of the city. In the face of successive natural hazards that caused human loss and material damage, it was necessary to organize the city's disaster risk management. One of the preventive actions developed by the municipality of Blumenau in partnership with schools is the School Civil Defense Program, whose objective is to make communities safer by giving classes on natural disaster prevention to children and teens. The present work proposes to analyze the risk perception of these students through participant observation and literature and documentary research. It is noted in this article that risk perception makes students more capable of prevention and resilience actions and behaviors.

Keywords: Risk perception, education, prevention, natural hazards, disaster risk management.

\footnotetext{
* O texto deste artigo corresponde a uma comunicação apresentada no IV Congresso Internacional de Riscos, tendo sido submetido em 17-05-2017, sujeito a revisão por pares a 26-09-2017 e aceite para publicação em 07-02-2018. Este artigo é parte integrante da Revista Territorium, $n .{ }^{\circ} 25$ (II), 2018, ${ }^{\circ}$ RIscos, ISSN: 0872-8941.
} 


\section{Introdução}

Desastres naturais causaram 700 mil mortes e afetaram mais de 1,5 bilhão de pessoas no mundo de 2005 a 2015, período que compreende o Marco de Hyogo, assinado por 168 países comprometidos a adotar medidas para redução de risco de desastres (UNISDR, 2015). Sob a ameaça constante de novos eventos, as sociedades modernas são desafiadas a lidar com os riscos para se proteger, como defende Ulrich Beck (2011). Compreendê-los por meio da educação é uma das prioridades do Marco de Sendai, documento em vigor assinado por 187 países comprometidos a adotar medidas para redução de risco de desastres entre 2015 e 2030. Envolver crianças e adolescentes por meio do processo de ensino e aprendizagem para perceber os riscos tornase um caminho para promover o incrementos de ações e comportamentos de prevenção e potenciar capacidades de resiliência.

No Brasil, o Atlas Brasileiro de Desastres Naturais - 1991 a 2012, elaborado pelo Centro Universitário de Estudos e Pesquisas sobre Desastres (CEPED), da Universidade Federal de Santa Catarina (UFSC), aponta que no período de 2000 a 2010 há registo de ocorrência de 38.996 desastres naturais, sendo que eventos de estiagem, seca, inundação brusca e alagamento são os mais recorrentes no país (CEPED/UFSC, 2013). Blumenau entra nesses números, contabilizando 92 inundações desde em 1850, conforme registos da Defesa Civil municipal, além dos movimentos de massa.

Diante desse contexto e com o amparo da Lei 12.608/2012, que institui a Política Nacional de Proteção e Defesa Civil, foi necessário estruturar a gestão de risco de desastres do município, resultando na criação da Secretaria de Defesa do Cidadão. Uma das ações de prevenção desenvolvidas pelo órgão em parceria com as escolas é o Programa Defesa Civil na Escola, criado em 2013 e cujo objetivo é tornar as comunidades mais seguras a partir do processo de ensino e aprendizagem de crianças e adolescentes.

O presente trabalho propõe-se a analisar a percepção de risco dos alunos que integram o Programa Defesa Civil na Escola, por meio dos desenhos e redações, observação participante e pesquisa bibliográfica. 0 programa, iniciado em 2013, atende anualmente alunos de $4^{\circ}$ ou $5^{\circ}$ ano de dez escolas públicas e particulares de Blumenau, escolhidas estrategicamente por terem em sua área de abrangência locais atingidos por inundações ou deslizamentos.

Observou-se que o trabalho de prevenção nas escolas tem servido de incentivo para que os alunos participem de forma consciente do processo de transformação do cenário da comunidade, tornando-se protagonistas e corresponsáveis pela gestão de risco de desastres de Blumenau.
O presente trabalho começa pela concetualização de desastres naturais, risco e percepção de risco, resiliência e prevenção. Em seguida, discute de que maneira a educação é uma ferramenta de redução de risco de desastre e como ela é abordada em documentos que tratam de redução de riscos. Depois, 0 artigo faz, ainda, o percurso histórico da investigação em desastres em Blumenau e a apresentação do Programa Defesa Civil na Escola. Por fim, apresentamse os resultados com a análise da percepção de risco dos alunos participantes do programa.

\section{Desastres naturais e a percepção de risco}

Os desastres naturais pautam a agenda internacional desde a década de 1990, após uma sucessão de eventos com desencadeadores naturais entre os anos 1970 e 1990, em países com população mais vulnerável social, econômica e politicamente. São exemplos desse período: terremoto seguido de avalanche na costa e serra do Peru e ciclone tropical em Bangladesh (1970), terremoto na Nicarágua (1972), seca na Etiópia (1973), furacão Fifi em Honduras, terremoto na China e inundação em Bangladesh (1974), terremoto na Guatemala e terremoto na China (1976), terremoto no Irã (1978), terremoto na Itália e inundação na China (1980), seca em Moçambique (1981), terremoto na Colômbia e seca na Etiópia e no Sudão (1983), terremoto no México, tempestade em Bangladesh, seca em Moçambique e deslizamentos decorrentes de vulcanismo na Colômbia (1985), vulcanismo em Camarões e terremoto em El Salvador (1986), terremoto no Equador (1987), terremotos na União Soviética, inundação em Bangladesh e furacões na América Central (1988), inundação na China (1989) e terremoto no Irã (1990) (EMDAT, 2017).

A Organização das Nações Unidas (ONU) inicia, então, um debate com 140 nações, a fim de reduzir números de vítimas e danos, e estabelece a Década Internacional para Redução de Desastres Naturais (DIRDN) com recomendações para os países reduzirem os impactos dos desastres entre 1990 e 2000.

Almeida (2015, p.3) afirma que a década "foi, em larga medida, consequência de duas questões interrelacionadas que permeavam o debate internacional nas décadas de 1970-80: os desafios do desenvolvimento econômico e grande onda de desastres que solapou vários países nesse período". Os impactos gerados pelos desastres naturais durante essa fase marcada pelo aumento da frequência e intensidade dos eventos "constitui apenas o ponto mais evidente de uma longa cadeia de interações recíprocas estabelecidas entre sociedade-natureza" (Mattedi e Butzke, 2001, p. 2).

Ao fim dos dez anos, concluiu-se que os resultados para reduzir os números de vítimas, danos materiais, sociais, ambientais e econômicos não foram alcançados, mas que a cultura de prevenção de desastres seria o caminho para obter melhores resultados. 
A década marcou também o início de um progresso de órgãos internacionais com a Conferência Mundial de Redução de Desastres em Yokohama, no Japão (1994), a criação do Escritório das Nações Unidas para a Redução do Risco de Desastres (UNISDR) (1999) e da Estratégia Internacional para Redução de Desastres (EIRD/ONU) (2000). Era preciso que as estratégias para a redução dos riscos de desastres naturais e ações de prevenção fossem prioridade e tivessem dimensão política ampla, na qual a responsabilidade deveria ser compartilhada entre todas as nações.

A EIRD (2004), documento sucessor à DIRDN, afirma que nos últimos 30 anos aumentaram tanto o número de desastres naturais como as populações afetadas. A EIRD considera esses desastres como:

\section{“[...] interrupção séria do funcionamento de uma comunidade ou sociedade que causa perdas humanas elou importantes perdas materiais, econômicas ou ambientais, que excedem a capacidade de a comunidade ou sociedade afetada para fazer frente à situação utilizando seus próprios recursos. Resulta da combinação de ameaças, condições de vulnerabilidade $e$ insuficientes capacidades ou medidas para reduzir as consequências negativas do potencial de risco" (EIRD/ONU, 2004, p. 17).}

Para completar a agenda internacional, os desastres naturais foram o centro do debate em 2005, quando foi instituído o Marco de Ação de Hyogo, no qual 168 países se comprometeram a adotar medidas para redução de risco de desastres no decênio de 2005 a 2015. Atualmente, está em vigor pelos próximos 15 anos o Marco de Ação de Sendai, adotado durante a "III Conferência Mundial sobre a Redução de Riscos de Desastres” da ONU, realizada em 2015 pela ONU, em Sendai, no Japão, com propostas para aumentar a resiliência das comunidades, compreender os riscos do desastre e melhorar a preparação, a fim de proporcionar uma resposta eficaz no pós-evento.

Os desastres naturais começaram a fazer parte da discussão científica nas últimas quatro décadas, principalmente no campo das Ciências da Terra e, mais tarde, pelas Ciências Sociais. É dessa área que partem os debates científicos mais calorosos sobre o conceito e sua relação com a natureza e a sociedade (Douglas e Wildavski, 1983; Beck, 1996; Almeida, 2015; Mattedi e Butzke, 2001). Almeida (2015, p. 2) defende que o conceito de desastre não é uma "consequência causal de uma ameaça (hazard) natural - furacões, enxurradas, enchentes, deslizamentos de terra, terremotos, etc - mas como o resultado do choque entre uma ameaça natural e um agrupamento humano vulnerável". Já Mattedi e Butzke separam os conceitos sob duas teorias: a dos Hazards e a dos Desastres. A primeira "desenvolvida do ponto de vista geográfico, que enfatiza os aspectos naturais", e a segunda, "desenvolvida do ponto de vista sociológico, que enfatiza os aspectos sociais" (Mattedi e Butzke, 2001, p. 3).

No Brasil, a Instrução Normativa n. ${ }^{\circ} 01$ de 24 de agosto de 2012 conceitua desastre como:

"[...] resultado de eventos adversos, naturais ou provocados pelo homem sobre um cenário vulnerável, causando grave perturbação ao funcionamento de uma comunidade ou sociedade envolvendo extensivas perdas e danos humanos, materiais, econômicos ou ambientais, que excede a sua capacidade de lidar com o problema por meios próprios" (BRASIL, 2012).

Nesse caso, os riscos são diretamente ligados aos fenômenos naturais, como classificados no Brasil, pela Codificação Brasileira de Desastres (BRASIL, 2012), em riscos geológicos, hidrológicos, meteorológicos, climatológicos e biológicos.

Para reduzir os riscos de desastres naturais, é necessária uma sucessão permanente de esforços, nos quais diferentes campos da atividade social, econômica, governamental e profissional estejam envolvidos em ações de prevenção e que visem a construção da resiliência nas comunidades.

Ulrich Beck (2011) trouxe, nos anos 1980, a chamada Sociedade do Risco, na qual o pesquisador relaciona a interação da sociedade moderna com a natureza onde o risco torna-se o marco temático de uma era. $\mathrm{A}$ Sociedade do Risco, que descreve Beck, é aquela que está sob uma ameaça constante de riscos que não podem ser influenciados pelo tempo, espaço, e são distribuídos entre as classes sociais, apesar de que todos podem ser, de alguma maneira, afetados por uma catástrofe: "risco é um fenômeno socialmente construído, em qual algumas pessoas têm uma maior capacidade de definir riscos do que outros" (Beck, 2006, p. 333).

0 presente artigo considera que os riscos são socialmente construídos e dependem do conhecimento da situação à qual se está exposto e do grau de vulnerabilidade. Já resiliência é entendida, de acordo com a Terminologia sobre a Redução de Risco de Desastre da UNISDR (2009, p.28), como "a capacidade de um sistema, comunidade ou sociedade exposto a riscos de resistir, absorver, adaptar-se e recuperar-se dos efeitos de um perigo de maneira tempestiva e eficiente".

Pioneiros nos estudos da percepção de risco dentro das Ciências Sociais e trazendo o conceito dentro da teoria cultural, Mary Douglas e Aaron Wildavsky (1983) afirmam que os riscos são ocultos, involuntários e selecionados pelas pessoas, e essa seleção depende das crenças, valores e práticas em um contexto. No livro Risk and Culture (Risco e Cultura), os pesquisadores explicam que 
a maneira como as pessoas percebem os riscos tem a ver com seu modo de ver o mundo, ou seja:

“A percepção do risco é um processo social. Toda sociedade depende de combinações de confiança e medo. [...] Alguns medos são físicos, outros são sociais. [...] Os princípios sociais que guiam o comportamento afetam o julgamento sobre quais medos devem ser mais temidos, quais riscos valem a pena ser arriscados, e quem deve estar apto a arrisca" (Douglas e Wildavsky 1983, p. 6).

A teoria cultural do risco, de Douglas e Wildavsky (1983), aponta um caminho para entender como as pessoas podem mitigar os riscos, minimizando os danos causados por desastres naturais. Por isso, os autores defendem que questões sobre níveis aceitáveis de risco devem ser explicadas através de como as pessoas ignoram certos riscos e aceitam outros, selecionando determinados aspectos baseados em características socioculturais para tomar essa decisão (Douglas e Wildavsky, 1983, p.9).

Os pesquisadores resumem esta relação entre a cultura e os fenômenos naturais, ao afirmarem que "o risco é a consequência direta dos perigos inerentes à situação física, enquanto atitudes em relação ao risco dependem da personalidade de cada indivíduo" (Douglas e Wildavsky, 1983, p. 193).

O risco faz parte da vida em sociedade e sempre esteve marcado na história, mas os desastres naturais nunca se fizeram tão presentes como no mundo moderno. Conhecer os riscos é, de certa forma, estar preparado para o que antecede o desastre natural. A vulnerabilidade de uma comunidade está diretamente relacionada com a consciência das ameaças do perigo: " $a$ percepção do risco varia segundo a sensibilidade de cada pessoa, comunidade e governo. Ter conhecimento das ameaças e da vulnerabilidade real, assim como dispor de informação precisa pode influenciar essa percepção" (Vensdruscolo e Kobiyama, 2007, p. 15).

Levar a cultura de prevenção através do ensino e aprendizagem em sala de aula é auxiliar na percepção de risco de crianças e jovens. Se os riscos de desastres naturais são socialmente construídos, cabe à sociedade julgar o que é, ou não, um risco e, por isso, é a percepção do risco que se faz no presente que pode determinar uma ação no futuro.

\section{A educação como ferramenta de redução de risco de desastres}

De acordo com um relatório publicado em 2016 pelo Centro de Investigação sobre a Epidemiologia dos Desastres (CRED) e pela Estratégia Internacional para a Redução de Desastres (UNISDR), entre 1995 e 2015 foram registradas 6.457 catástrofes climáticas, que afetaram mais de 4 bilhões de pessoas e representaram um prejuízo maior que US\$ 1.891 bilhão, correspondente a perdas atribuídas aos riscos naturais durante o período de vinte anos.

Diante desta problemática, a gestão de risco de desastres se constitui como um importante desafio da contemporaneidade, tanto para os gestores públicos quanto para a sociedade em geral. A UNISDR (2009, p. 19) define a gestão de riscos de desastres como: "Um processo sistemático de utilizar diretrizes administrativas, organização, habilidades e capacidades operacionais para executar políticas e fortalecer as capacidades de enfrentamento, com a finalidade de reduzir o impacto adverso de ameaças naturais e a possibilidade de que ocorra um desastre".

Assim, há algumas décadas, governos de todo o mundo vem se reunindo para discutir sobre os desastres naturais e a melhor forma de evitar ou reduzir a ocorrência destes. As estratégias de ação, que antes se centravam na resposta aos eventos naturais extremos, têm-se direcionado à medidas preventivas relacionadas a intervenção sobre situações e contextos de risco.

Conforme Narváez, Lavell e Ortega (2009, p. 35) “A gestão de riscos de desastre, como conceito central da discussão em torno da intervenção no risco de desastres, data essencialmente da última metade dos anos noventa". Neste período, um importante avanço ocorreu, que foi o entendimento de que não basta administrar os desastres, mas é necessário, prever, planejar e reduzir os riscos, alterando o foco da abordagem da "gestão de desastres" para a "gestão de riscos de desastres". Essa alteração foi essencial para que os países adotassem estratégias para reduzir as vulnerabilidades e assim tornarem-se mais resistentes às ameaças naturais.

Como parte desse processo de mudança, alguns eventos e acordos internacionais foram importantes e contribuíram de forma significativa para o desenvolvimento de políticas e estratégias para a redução do risco de desastres, através de medidas que promovem a mudança da cultura de percepção de risco através da educação.

No ano de 1989, a Organização das Nações Unidas (ONU) aprovou em Assembleia Geral a Resolução n 44/236, de 22 de dezembro de 1989, que definiu o ano de 1990 como o início da Década Internacional para a Redução de Desastres (DIRDN). Ainda nesta Assembleia Geral, ocorrida em 1989, a ONU convocou a Conferência das Nações Unidas sobre o Meio Ambiente e Desenvolvimento, através da Resolução $n^{\circ} 44 / 228$ de 1989, que foi realizada em 1992 e foi considerada o encontro mundial mais importante do final do século. Os compromissos assumidos pelos países durante a Conferência das Nações Unidas sobre o Meio Ambiente e Desenvolvimento/ECO92 levaram os participantes a preparar uma agenda de 
trabalho para o próximo século: a Agenda 21. Entre as áreas de atuação estabelecidas pela Agenda 21 está a promoção do ensino, da conscientização e do treinamento. De acordo com a Conferência das Nações Unidas - Agenda 21:

\begin{abstract}
"O ensino, inclusive o ensino formal, a consciência pública e o treinamento devem ser reconhecidos como um processo pelo qual os seres humanos $e$ as sociedades podem desenvolver plenamente suas potencialidades. $O$ ensino tem fundamental importância na promoção do desenvolvimento sustentável e para aumentar a capacidade do povo para abordar questões de meio ambiente e desenvolvimento. [...] Tanto o ensino formal como o informal são indispensáveis para modificar a atitude das pessoas, para que estas tenham capacidade de avaliar os problemas do desenvolvimento sustentável e abordá-los. O ensino é também fundamental para conferir consciência ambiental e ética, valores e atitudes, técnicas e comportamentos em consonância com o desenvolvimento sustentável e que favoreçam a participação pública efetiva nas tomadas de decisão" (ONU, 1995, p. 429).
\end{abstract}

Na sequência, em 1994, durante a Conferência Mundial Sobre a Redução de Riscos de Desastres, em Yokohama, no Japão, foi definida a "Estratégia e Plano de Ação de Yokohama para um Mundo mais Seguro" e diretrizes para a prevenção, preparação e mitigação dos desastres naturais. Este documento estabelece como um de seus princípios que “ $A$ vulnerabilidade pode ser reduzida através da aplicação de métodos apropriados e padrões de desenvolvimento focado em proporcionar educação e formação adequadas para a comunidade" UNISDR (1994, p. 7).

A Estratégia de Yokohama deixou algumas lacunas e desafios que foram identificadas em 2005, durante a Segunda Conferência Mundial sobre a Redução de Desastres, realizada em Hyogo, no Japão. Uma das áreas prioritárias do Marco de Ação de Hyogo era a "gestão do conhecimento e educação". O objetivo principal era reduzir consideravelmente até 2015 , as perdas humanas, sociais, econômicas e ambientais das comunidades e dos países (UNISDR, 2005).

O marco definiu ações prioritárias que serviram para orientar estados, organizações e atores em todos os níveis. Entre elas, destacamos "Utilizar o conhecimento, a inovação e a educação para criar uma cultura de segurança e resiliência em todos os níveis." UNISDR (2005, p. 9). O documento supracitado indica ainda que “As catástrofes podem ser substancialmente reduzidas se as pessoas estiverem bem informadas e motivadas para uma cultura de prevenção e resiliência de desastres que, por sua vez, exige a coleta, compilação e divulgação de conhecimentos e informações relevantes sobre riscos, vulnerabilidades e capacidades" UNISDR (2005, p. 9).

Com relação às atividades propostas pelo Marco de Ação de Hyogo UNISDR (2005, p. 9), no eixo “Educação $e$ formação", podemos destacar a promoção da inclusão de conhecimento sobre redução de riscos entre jovens e crianças, e promoção de programas e atividades em escolas e instituições de ensino superior para aprender a minimizar os perigos.

Recentemente, em 2015, durante a Terceira Conferência Mundial sobre a Redução de Riscos de Desastres, realizada em Sendai, Miyagi, no Japão, os países reiteraram o seu compromisso com a redução do risco de desastres e com o aumento da resiliência e adotaram o marco, que está em vigor até 2030 e tem como objetivo:
"Prevenir novos riscos de desastres e reduzir os riscos de desastres existentes, através da im- plementação medidas econômicas, estruturais, jurídicas, sociais, de saúde, culturais, educacio- nais, ambientais, tecnológicas, políticas e insti- tucionais integradas e inclusivas que previnam e reduzam a exposição a perigos e a vulnerabi- lidade a desastres, aumentar a preparação para resposta e recuperação, e, assim, aumentar a resiliência" (UNISDR, 2015, p. 7).

Nesta última conferência mundial, os países destacaram a importância e urgência na integração de esforços dos setores público e privado, organizações da sociedade civil, bem como as instituições científicas e de pesquisa, para trabalharem juntos na criação de políticas, planos, programas e orçamentos de todos os níveis, em busca do desenvolvimento sustentável.

Para uma gestão eficaz e eficiente dos riscos de desastres, o documento também define estratégias a serem seguidas no âmbito global e regional e o estímulo à cultura de prevenção através da educação. Novamente aparece como uma das áreas prioritárias para a redução dos riscos de desastres e o desenvolvimento sustentável:

\footnotetext{
"Desenvolver campanhas globais e regionais eficazes como instrumentos para a sensibilização e educação da sociedade, com base em campanhas já existentes (por exemplo, a iniciativa "Um milhão de escolas e hospitais seguros", a campanha "Construindo cidades Resilientes: minha cidade está se preparando", - Prêmio Sasakawa das Nações Unidas para a Redução de Desastres e o Dia Internacional das Nações Unidas para a Redução de Desastres), a fim de promover uma cultura de prevenção de desastres, resiliência e cidadania responsável, gerar compreensão dos riscos de desastres, apoiar a aprendizagem mútua, compartilhar experiências. Incentivar as partes interessadas
} 
públicas e privadas a se engajar e participar ativamente de tais iniciativas e a desenvolver novas iniciativas nos níveis local, nacional, regional e global" (UNISDR, 2015, p. 12).

Segundo Marques et al. (2014, p. 14), a educação ambiental, termo que começou a ser discutido em 1970, com a onda de preocupação com a intensidade dos problemas ambientais marcada pela Conferência de Estocolmo, deve ser uma ferramenta contínua, integrada e interdisciplinar, focada em ações educativas "em contextos formais e informais, orientando para a solução dos problemas voltados para a realidade local, $e$ em seguida se expanda de forma global".

No Brasil, a Lei $N^{\circ} 12.608 / 2012$, que instituiu a Política Nacional de Defesa Civil (PNPDEC) e dispõe sobre Sistema Nacional de Proteção e Defesa Civil (SINPDEC) e o Conselho Nacional de Proteção e Defesa Civil (CONPEC), representa um marco no que se refere às definições de responsabilidades individuais e compartilhadas entre União, Estados, Municípios e sociedade civil, para a adoção de medidas de prevenção, mitigação, preparação, resposta e reconstrução.

A Lei $N^{\circ} 12.608 / 2012$ fomenta o desenvolvimento de uma nova cultura de prevenção, através da percepção e gestão dos riscos, além da valorosa orientação para a incorporação da temática às agendas do planeamento urbano e gestão pública. De acordo com seu Art. $3^{\circ}$, parágrafo único:

“A PNPDEC deve integrar-se às políticas de ordenamento territorial, desenvolvimento urbano, saúde, meio ambiente, mudanças climáticas, gestão de recursos hídricos, geologia, infraestrutura, educação, ciência e tecnologia e às demais políticas setoriais, tendo em vista a promoção do desenvolvimento sustentável" (BRASIL, 2012).

No que se refere à inclusão da temática desastres na educação formal, a Lei $N^{\circ} 9.394 / 1996$, que estabelece as diretrizes e bases da educação nacional, prevê que os currículos de educação infantil, do ensino fundamental e do ensino médio devem seguir a base nacional comum, mas respeitar as características regionais e locais da sociedade, da cultura, da economia e dos educandos. No seu Art. 26, parágrafo sétimo, a lei prevê que " $A$ integralização curricular poderá incluir, a critério dos sistemas de ensino, projetos e pesquisas envolvendo os temas transversais de que trata o caput".

Diante do contexto onde o ensino e aprendizagem tornou-se uma das ferramentas para redução de riscos de desastres naturais. Blumenau, em consonância com as diretrizes internacionais e amparada pelas leis brasileiras, reconheceu o Programa Defesa Civil na Escola através do Conselho Municipal de Educação, pelo Parecer
$N^{\circ}$. 01/2013, sob o Processo $N^{\circ}$. 060/2013. De acordo com Marques et al. (2014, p. 13), a educação ambiental deve ter ações recorrentes com informações divulgadas por meio de campanhas, eventos e mobilizações que despertem nas comunidades o senso de responsabilidade para com o meio ambiente, e, com isso, "espera-se criar condições favoráveis para garantir o envolvimento e a participação de todos, utilizando para isso diversas ações que visam melhorar a qualidade de vida dos indivíduos, e orientar o uso racional dos recursos e serviços que a natureza oferece".

Envolver crianças e adolescentes com os princípios de proteção e defesa civil, a fim de estimular desde cedo a percepção de risco de desastres, foi uma estratégia adotada para evitar ou minimizar o impacto dos eventos naturais extremos que atingem o município desde a sua fundação.

\section{Blumenau e o Programa Defesa Civil na Escola}

Blumenau, localizada na bacia hidrográfica do rio ItajaíAçu, registrou desde a sua fundação, no ano de 1850 , até 2016, 92 inundações e movimentos de massa ocorridos em diversas regiões do município, devido à relação entre ocupação irregular e aspectos do meio físico como o relevo fortemente acidentado. Segundo Vieira et al. (2016, p.7), a formação das áreas de risco foi "potencializada pela morfologia resultante da ocupação de Blumenau em seu período colonial que começa nas planícies fluviais, com as ruas principais paralelas ao rio, se estendendo em direção às encostas".

Se, ao longo dos anos, as áreas da superfície foram inundadas (quando o rio Itajaí-Açu atinge $8,00 \mathrm{~m}$ é considerado inundação), a população buscou nas áreas de encosta um lugar seguro e longe do rio para viver. As maiores inundações foram registradas nos anos de: 1852 na qual o rio chegou a $16,30 \mathrm{~m}$, em 1880 a $17,10 \mathrm{~m}$, em 1911 a 16,90, em 1983 a 15,34 e 1984 a 15,46m.
"Em Blumenau, assim como na maior parte das cidades brasileiras, o crescimento urbano ocorreu a partir da década de 1970, quando os riscos de deslizamentos tornaram-se mais evidentes, principalmente no setor sul e oeste, onde o releo é mais acidentado e a ocupação mais densa" (Vieira e Furtado, 2005, p.57).

Mas foi no ano de 2008 que ocorreu o pior desastre natural do município, no qual 24 pessoas morreram, 5209 ficaram desabrigados e 25 mil desalojados (Blumenau, 2008). O cenário de desastre, ocorrido em 22 e 23 de novembro de 2008, foi causado por um acumulado de chuvas contínuas desde julho daquele ano, somado aos $250 \mathrm{~mm}$ de precipitação que caiu naqueles dois dias (Pozzobon, 2013), ocasionando uma inundação de 11,52 metros e mais de 3 mil ocorrências de deslizamentos em todas as regiões do município. 
A catástrofe de 2008 apontou um novo desafio à gestão de riscos de desastres naturais ao município: se antes o principal foco eram as inundações e a resposta ao desastre, era preciso agora encontrar estratégias destinadas a mitigar os deslizamentos e investir em prevenção.

Frente ao marco histórico de 2008, ações de prevenção foram ganhando força na gestão pública do município, como a estruturação da Secretaria de Defesa do Cidadão, a criação de um setor de Geologia, do Sistema Monitoramento e Alerta de Eventos Extremos de Blumenau (AlertaBlu) e do Programa Defesa Civil na Escola, em 2013.

Como forma de minimizar os efeitos destes eventos e considerando a inexistência de um programa específico de ações efetivas de prevenção de desastres, no município, buscou-se introduzir em Blumenau, através da Diretoria de Defesa Civil, ações em escolas da rede pública e particular que promovessem a prevenção e potencializassem uma mudança cultural de proteção individual e coletiva em situações de desastres.

Em consonância com as Leis $\mathrm{N}^{\circ}$. 12.608 de 10/04/2012, a Lei $N^{\circ} .9394$ de 20/12/1996 e com as diretrizes estabelecidas por protocolos internacionais, o Programa Defesa Civil na Escola iniciou as atividades em 2013 em duas escolas, como projeto piloto. 0 objetivo do Programa é tornar as comunidades mais seguras a partir do espaço escolar, com atividades desenvolvidas em harmonia com a proposta político pedagógica de cada escola com foco na educação ambiental para prevenção de desastres.

Atualmente, participam alunos dos $4^{\circ}$ aos $6^{\circ}$ anos do ensino fundamental e de acordo com a metodologia do Programa, os encontros dos alunos com a equipe da Defesa Civil são divididos em três módulos de aproximadamente 45 minutos: Módulo 1 - Noções básicas de Defesa Civil; Módulo 2 - Percepção de Risco e Módulo 3 - Desastres, que são passados através da apresentação de slides e de vídeos educativos sobre o tema.

No primeiro encontro, são trabalhados os conceitos e surgimento da Defesa Civil e suas ações, histórico de desastres no município e o papel da escola e das crianças na prevenção de desastres. No segundo encontro, com o tema Percepção de Riscos, a apresentação traz o conceito de risco e informações orientativas sobre como identificar o risco e como tornar a casa mais segura, destacando a importância do uso de calhas no telhado, o que plantar e o que não plantar em encostas e sobre a importância de fazer a drenagem e canalização das águas da chuva. 0 terceiro encontro tem como tema Desastres, onde é trabalhado o conceito de desastres, suas origens e os principais desastres naturais ocorridos no município. Neste dia também é entregue um formulário para desenho ou texto, onde os alunos desenham ou escrevem o que aprenderam no decorrer das aulas.
Ao final, a escola e cada turma participante recebem um certificado de Parceira da Defesa Civil e a visita da cadela Mayla, mascote dos Projetos de Prevenção da Defesa Civil que além de participar dos encontros com as crianças, tem o papel de lembrar as famílias que ao sair do seu local em risco não devem abandonar seus animais de estimação.

A cada ano, o Programa Defesa Civil na Escola visa estender o projeto a unidades de ensino de todas as regiões do município que, em sua maioria, fazem parte dos 60 abrigos de Defesa Civil cadastrados no Plano de Contingência. A equipe, inicialmente era composta por duas assistentes sociais do quadro de funcionários da Defesa Civil, ficando a coordenação por conta de uma delas. Mais tarde, houve o apoio de técnicos administrativos, agentes de Defesa Civil e estagiários para contribuir com o planeamento, atividades burocráticas e execução do Programa. Desde a sua criação em 2013, até 2016, o Programa contemplou 32 escolas públicas e particulares. No primeiro ano de execução o Programa foi desenvolvido de forma piloto em 02 escolas e nos 3 anos subsequentes foram atendidas 10 estabelecimentos de ensino por ano. Nestas 32 escolas, aproximadamente 3 mil alunos participaram presencialmente das aulas do Programa Defesa Civil na Escola.

O objetivo do Programa é de que os participantes reproduzam no bairro o que aprenderam e vivenciaram no para que a comunidade seja capaz de identificar os riscos, se prevenir e se autoproteger nas situações de calamidade. Entende-se que a escola é um espaço privilegiado para a educação ambiental e principalmente para promover mudanças que contribuam para a melhoria da qualidade de vida das comunidades. Espera-se que alunos participantes do Programa Defesa Civil na Escola tornem-se protagonistas da história de mudança de vida na sua comunidade. Uma mudança de vida saudável que contribua com a minimização do impacto dos desastres e que promova a cultura de prevenção, fortalecendo ainda o processo de resiliência do município.

\section{Procedimentos metodológicos}

0 recorte temporal para a pesquisa deste artigo é o ano de 2016, no qual o Programa atendeu sete escolas da rede municipal, duas escolas estaduais e uma da rede privada de ensino. Dentre essas, as escolas João Joaquim Fronza e Santos Dumont e o Colégio Sagrada Família são destaque para a elaboração deste trabalho por meio da análise da percepção de risco de desastres naturais a partir do material gráfico e textos produzido pelos alunos e observação participante; já que as autoras estavam presentes durante os encontros e foram mediadoras do Programa Defesa Civil na Escola. A proposta dos desenhos e redações é identificar através de expressões gráficas o que os alunos apreenderam durante as aulas, e com com isso avaliar o conhecimento desenvolvido através do conteúdo ministrado. 
Na Escola Básica Municipal João Joaquim Fronza, 37 alunos do $4^{\circ}$ ano participaram das atividades em junho. A unidade escolar está localizada no bairro Itoupavazinha, região que possui registos de inundações e deslizamentos. A referida escola é um dos 60 abrigos de Defesa Civil cadastrados no Plano de Contingência contra Inundações e Deslizamentos do município de Blumenau.

Já na Escola de Educação Básica Santos Dumont, 49 alunos participaram do Programa Defesa Civil na Escola em agosto e setembro. Trata-se de uma escola da rede estadual, atendendo alunos do ensino fundamental e do ensino médio. Está localizada na região sul do município e é também cadastrada como abrigo, acolhendo desabrigados atingidos por inundações e deslizamentos de terra.

No Colégio Sagrada Família, um total de 86 alunos fez parte do Programa de prevenção em outubro, sendo a segunda escola da rede particular de ensino a participar. Localizado na região central do município, o colégio apesar de ser atingido em sua parte mais baixa por inundação, também é um abrigo cadastrado. 0 material analisado foi o seguinte:

- E.B.M. Joaquim Fronza - junho de 2016:

- 24 desenhos;

- 17 redações.

- E.E.B. Santos Dumont - agosto e setembro de 2016:

- 24 desenhos;

- 25 redações.

- Colégio Sagrada Família - agosto de 2016:

- 72 desenhos;

- 86 redações.

Para analisar a percepção de risco de desastres naturais dos alunos do Programa em 2016 por meio de desenhos e redações foram selecionados critérios que configuram uma situação de risco apresentados em sala de aula em cartilhas e vídeos da Defesa Civil. Foram categorizados os seguintes itens:

- Definição e conceito de Defesa Civil e de desastres;

- Importância da solicitação de vistoria e avaliação de situações de risco ou acionamento para emergência 199 - Defesa Civil;

- Lixo como causador de desastre;

- Não construir em encostas e morros;

- Monitoramento das condições do tempo e nível do rio através do AlertaBlu;

- Cobertura vegetal em encostas\capim vetiver;

- Não plantar bananeiras em encostas;

- Importância dos abrigos;

- Co-responsabilidade nas ações de Defesa Civil (somos todos nós);
- Importância do destino das águas pluviais e servidas;

- Cuidado com o surgimento de rachaduras na residência;

- Importância de calhas nos telhados.

\section{Resultados e discussões}

Após a seleção dos critérios de percepção de risco de desastre, o material coletado nas escolas, num total de 120 desenhos e 128 redações, foi analisado, bem como a interação dos alunos em sala. Ao avaliar o trabalhos concluímos que os objetivos foram alcançados, quando identificamos que o conhecimento foi desenvolvido e está registrado em forma de desenho ou escrita. Através da análise dos materiais gráficos, fica evidente a compreensão a cerca de alguns conteúdos tais como: o risco da ocupação nas encostas, o cuidado com o tipo de vegetação que deve ser utilizada em taludes, os cuidados com o lixo e a importância da drenagem pluvial Concluiu-se que noções de proteção individual, como a decisão por um terreno plano na hora da compra de um terreno, ou o não plantio de bananeiras em encostas, e princípios da Defesa Civil foram lembradas pelos participantes do Programa Defesa Civil na Escola nas três escolas selecionadas para este artigo (TABELA I).

Nos desenhos e redações surgiram com maior frequência o conceito e objetivo da Defesa Civil e desastres naturais como inundações e deslizamentos, não construir em encostas e morros, e a importância da vistoria e avaliação de situações de risco por meio do telefone da Defesa Civil, o 199.

\section{Escola Básica Municipal João Fronza}

Na Escola Básica Municipal João Joaquim Fronza, os alunos demonstraram, através dos desenhos e redações (nesta escola em formato de carta sobre o que foi aprendido) (fig.2), que as aulas do Programa Defesa Civil na Escola deixaram lições relacionadas à gestão de risco de desastres e a importância das ações desenvolvidas pela Defesa Civil. Os conteúdos que apareceram com maior frequência são referentes à construção de imóveis nas encostas e os perigos desta forma de ocupação. Outro aspecto recorrente diz respeito ao destino incorreta do lixo e sua relação com os alagamentos e deslizamentos (TABELA II). Ao total foram analisados 24 desenhos e 17 redações.

Os alunos referenciam a importância da vegetação nas encostas e foram apresentados exemplos de plantas que auxiliam na contenção das encostas e outras que potencializam a ocorrência de deslizamentos (fig. 1). O plantio de árvores de grande porte e a bananeira (vegetação comum na região) tiveram destaque como fatores que aumentam o risco de deslizamentos. Como exemplo de vegetação adequada para estabilizar encostas, os alunos indicaram o capim vetiver, espécie 
TABELA I - Critérios de percepção de risco.

$T_{A B L E}$ I - Features of risk perception.

\begin{tabular}{|l|l|l|l|l|}
\hline \multicolumn{1}{|c|}{ Critérios } & \multicolumn{1}{|c|}{$\begin{array}{c}\text { Escola } \\
\text { João } \\
\text { Fronza }\end{array}$} & $\begin{array}{c}\text { Escola } \\
\text { Santos } \\
\text { Dumont }\end{array}$ & $\begin{array}{c}\text { Colégio } \\
\text { Sagrada } \\
\text { Família }\end{array}$ & \multicolumn{1}{|c|}{ Total } \\
\hline $\begin{array}{l}\text { Definição e conceito de DC e de desastres. Identificação de ações de proteção e } \\
\text { segurança frente as chuvas que geram deslizamento enchente (8m) ou identificação } \\
\text { do símbolollogo e atividades parceiras. }\end{array}$ & 10 & 30 & 41 & 81 \\
\hline $\begin{array}{l}\text { Importância da solicitação de vistoria e avaliação de situações de risco ou } \\
\text { acionamento para emergência através do 199 - Defesa Civil. }\end{array}$ & 07 & 16 & 55 & 78 \\
\hline Lixo como causador de desastre & 15 & 08 & 33 & 56 \\
\hline Não construir em encostas ou morro. & 15 & 17 & 72 & 104 \\
\hline Monitoramento das condições do tempo e nível do rio através do AlertaBlu & 01 & 05 & 10 & 16 \\
\hline Cobertura vegetal em encostas/capim vetiver & 06 & 09 & 38 & 53 \\
\hline Não plantar bananeiras em encostas / Árvores grandes & 12 & 10 & 29 & 51 \\
\hline Abrigos & 02 & 13 & 18 & 33 \\
\hline Co-responsabilidade nas ações de Defesa Civil (somos todos nós) & 01 & 02 & 04 & 07 \\
\hline Importância do destino das águas pluviais e servidas & 03 & 01 & 13 & 17 \\
\hline Cuidado com o surgimento de rachaduras na residência & 01 & -- & 13 & 14 \\
\hline Importância de calhas nos telhados & 05 & 01 & 08 & 14 \\
\hline
\end{tabular}

Fonte: Defesa Civil de Blumenau / Source: Blumenau Civil Defense.

TABeLA II - Critérios de percepção de risco na Escola Básica Municipal João Fronza.

$T_{A B L E}$ II - Features of risk perception at João Fronza School.

\begin{tabular}{|l|l|l|l|}
\hline \multicolumn{1}{|c|}{ Critérios } & Desenho & \multicolumn{1}{|c|}{ Redação } & \multicolumn{1}{|c|}{ Total } \\
\hline $\begin{array}{l}\text { Definição e conceito de DC e de desastres. Identificação de ações de proteção e segurança } \\
\text { frente as chuvas que geram deslizamento e enchente (8m) ou identificação do símbolollogo } \\
\text { e atividades parceiras. }\end{array}$ & 03 & 07 & 10 \\
\hline $\begin{array}{l}\text { Importância da solicitação de vistoria e avaliação de situações de risco ou acionamento para } \\
\text { emergência através do 199 - Defesa Civil. }\end{array}$ & 04 & 03 & 07 \\
\hline Lixo como causador de desastre & 09 & 06 & 15 \\
\hline Não construir em encostas ou morro & 12 & 03 & 15 \\
\hline Monitoramento das condições do tempo e nível do rio através do AlertaBlu & $\cdots-$ & 01 \\
\hline Cobertura vegetal em encostas/capim vetiver & 04 & 02 & 06 \\
\hline Não plantar bananeiras em encostas / Árvores grandes & 07 & 05 & 12 \\
\hline Abrigos & 01 & 01 & 02 \\
\hline Co-responsabilidade nas ações de Defesa Civil (somos todos nós) & 01 & $\ldots$ & 01 \\
\hline Importância do destino das águas pluviais e servidas & 01 & 02 & 03 \\
\hline Cuidado com o surgimento de rachaduras na residência & $\ldots-$ & 01 & 01 \\
\hline Importância de calhas nos telhados & 01 & 04 & 05 \\
\hline
\end{tabular}

Fonte: Defesa Civil de Blumenau / Source: Blumenau Civil Defense.

que possui raiz profunda e a capacidade de estabilizar o solo e controlar a erosão. A Defesa Civil também foi mencionada em vários desenhos e redações vinculada à proteção e segurança da população em situações de desastres. A importância do destino correto das águas pluviais e servidas, a canalização e o uso de calhas nos telhados também foram indicados pelos alunos como práticas positivas. Em menor proporção, foram manifestadas orientações para não abandonar animais de estimação durante os desastres, não brincar com a água da enchente, cuidados com rachaduras nas residências e a existência dos abrigos de Defesa Civil. Em quase 
todos os desenhos, os alunos expuseram atitudes e suas consequências, representando fatores que podem ou não ocasionar desastres.

Além do material analisado, a participação nas aulas possibilitou constatar que há uma identificação, por parte dos participantes, com a temática abordada (fig. 2). Vários relatos indicaram que os alunos residem em áreas de risco e, entre uma aula e outra, traziam informações relacionadas a fatores de riscos identificados na comunidade ou na própria residência. Houve também

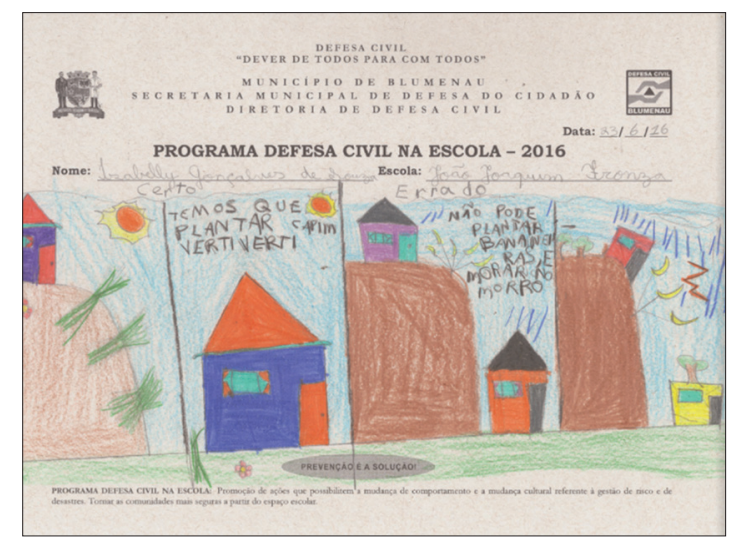

Fig. 1 - Desenho feito por uma aluna do $4^{\circ}$ ano da Escola João Fronza (Fonte: Defesa Civil de Blumenau).

Fig. 1 - Picture by a $4^{\text {th }}$ grade student at João Fronza School (Source: Blumenau Civil Defense).

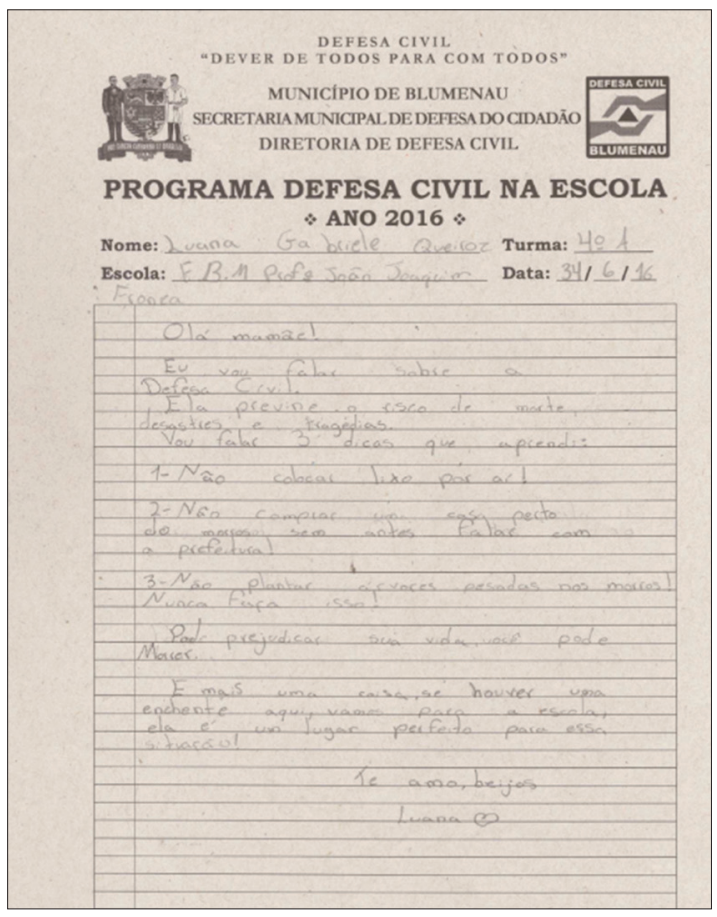

Fig. 2 - Redação feita por uma aluna do $4^{\circ}$ ano da Escola João Fronza (Fonte: Defesa Civil de Blumenau).

Fig. 2 - Text written by $a 4^{\text {th }}$ grade student at João Fronza School (Source: Blumenau Civil Defense). depoimentos de alunos que vivenciaram situações de desastres, sofreram danos e alguns que ficaram alojados temporariamente nos abrigos de Defesa Civil.

\section{Escola de Educação Básica Santos Dumont}

Na Escola de Educação Básica Santos Dumont, os participantes apontam principalmente a função da Defesa Civil diante de situações de risco como inundações e deslizamentos. Os alunos lembram, principalmente, do perigo que é construir em encostas sem acompanhamento técnico e construções irregulares e da Defesa Civil como um órgão para proteger as pessoas por meio da ligação para o 199. Foram analisados 24 desenhos e 25 redações (TABELA III) .

A proteção e a ajuda são os conceitos que mais aparecem em redações quando é citado a Defesa Civil, tanto antes, durante e depois de um desastre natural. A integração do órgão com outros setores da segurança pública do município, como Corpo de Bombeiros e Polícia, é referenciada nos textos como uma equipe disposta a ajudar a comunidade no transporte, alimentação, abrigo, proteção e reconstrução. O telefone 199 aparece, na maioria das representações, como um meio para pedir auxílio durante os desastres e para tirar dúvidas sobre construções em áreas de risco. Frases como "Se tiver qualquer problema ligue 199", "se estiver em apuros ligue para Defesa Civil”, "a Defesa Civil sempre vai cuidar de tudo", "gosto da Defesa Civil porque eles protegem as pessoas" aparecem em alguns dos textos, mencionando novamente como um órgão que ajuda a comunidade (fig. 3).

A importância da preservação da natureza, como não derrubar árvores, não cortar terrenos irregularmente, é lembrado pelos alunos, tanto em desenhos quanto em redações, e por isso foi acrescentado como critério

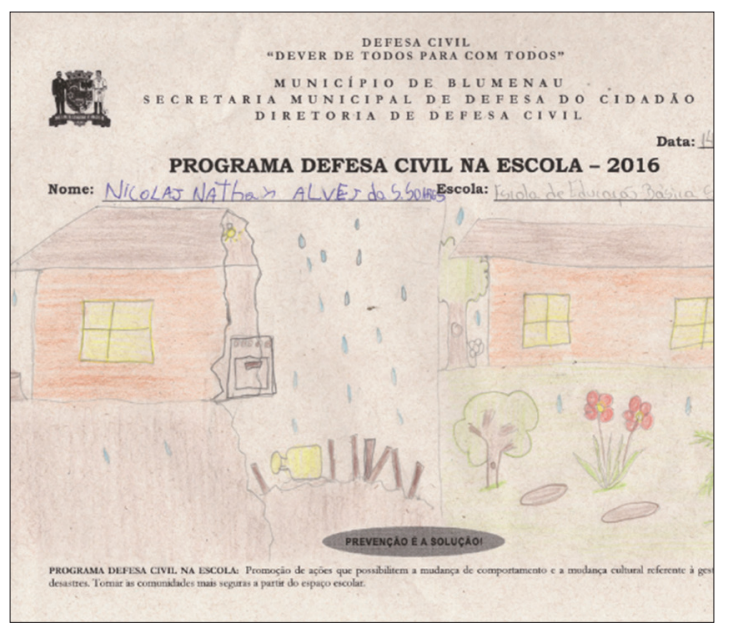

Fig. 3 - Desenho feito por um aluno do $4^{\circ}$ ano da Escola Santos Dumont (Fonte: Defesa Civil de Blumenau).

Fig. 3 - Picture by a $4^{\text {th }}$ grade student at Sagrada Família School (Source: Blumenau Civil Defense). 
TABELA III - Critérios de percepção de risco na Escola de Educação Básica Santos Dumont.

TABLE III - Features of risk perception at Santos Dumont School.

\begin{tabular}{|c|c|c|c|}
\hline Critérios & Desenho & Redação & Total \\
\hline $\begin{array}{l}\text { Definição e conceito de DC e de desastres. Identificação de ações de proteção e segurança } \\
\text { frente as chuvas que geram deslizamento e enchente }(8 \mathrm{~m}) \text { ou identificação do símbolollogo } \\
\text { e atividades parceiras. }\end{array}$ & 06 & 24 & 30 \\
\hline $\begin{array}{l}\text { Importância da solicitação de vistoria e avaliação de situações de risco ou acionamento para } \\
\text { emergência através do } 199 \text { - Defesa Civil. }\end{array}$ & 02 & 14 & 16 \\
\hline Lixo como causador de desastre & 03 & 05 & 08 \\
\hline Não construir em encostas ou morro & 13 & 04 & 17 \\
\hline Monitoramento das condições do tempo e nível do rio através do AlertaBlu & -- & 05 & 05 \\
\hline Cobertura vegetal em encostas/capim vetiver & 08 & 01 & 09 \\
\hline Não plantar bananeiras em encostas / Árvores grandes & 06 & 04 & 10 \\
\hline Abrigos & -- & 13 & 13 \\
\hline Co-responsabilidade nas ações de Defesa Civil (somos todos nós) & -- & 02 & 02 \\
\hline Importância do destino das águas pluviais e servidas & -- & 01 & 01 \\
\hline Cuidado com o surgimento de rachaduras na residência & -- & -- & -- \\
\hline Importância de calhas nos telhados & 01 & -- & 01 \\
\hline *Preservação da natureza & 03 & 02 & 05 \\
\hline
\end{tabular}

Fonte: Defesa Civil de Blumenau / Source: Blumenau Civil Defense.

nessa escola (fig. 4). Os desastres, segundo os alunos, são causados tanto pela natureza quanto pelo homem, e essa responsabilidade de ser também um causador de desastres naturais fica bem evidente no discurso nos alunos.

A percepção de risco fica explícita em textos e desenhos onde aparece um barranco, chuva e bananeiras. Essa combinação, citada durante os encontros, é um dos

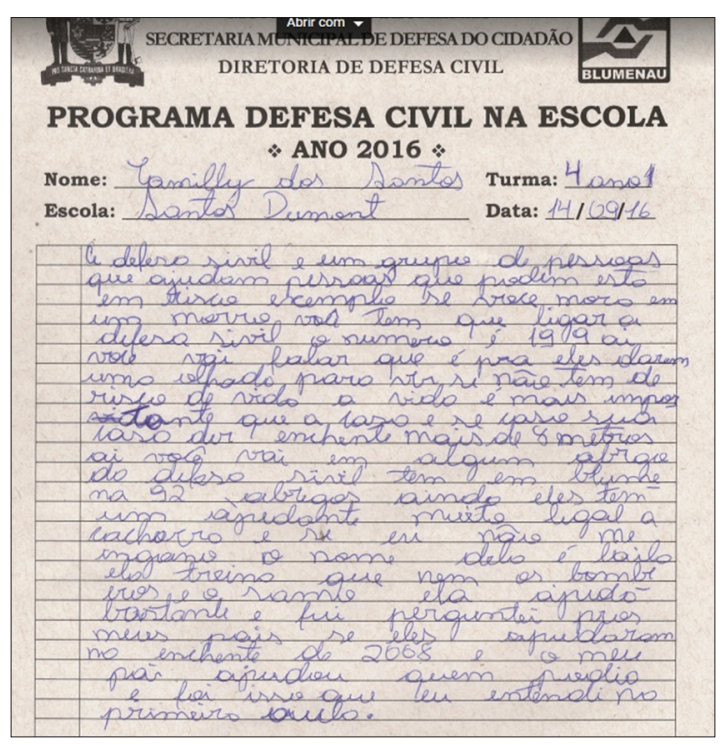

Fig. 4 - Redação feita por uma aluna do $4^{\circ}$ ano da Escola Santos Dumont (Fonte: Defesa Civil de Blumenau).

Fig. 4 - Text written by a $4^{\text {th }}$ grade student at Santos Dumont School (Source: Blumenau Civil Defense). exemplos mais lembrados pelos alunos. A importância de saber o nível que o rio tem de estar para atingir a casa e saber a previsão do tempo através do AlertaBlu também aparecem em redações dos participantes.

\section{Colégio Sagrada Família}

No Colégio Sagrada Família, foram analisados 72 desenhos e 86 redações (TABELA IV). Os alunos perceberam o risco, identificando em suas comunidades a presença de vários morros sendo cada vez mais ocupados por moradias construídas sem acompanhamento técnico, em locais de preservação ambiental e próximas aos rios. Ao longo das conversas em sala de aula, muitos também lembraram que apesar de não serem atingidos diretamente pelos desastres, ficam sem acesso às outras regiões. Grande parte dos alunos apontou o AlertaBlu como fonte de informações para monitoramento das situações de tempo e de desastres, e na ocasião, alguns baixaram o aplicativo em seus celulares.

De entre os conteúdos abordados durante as aulas, o tema da primeira aula que trata de noções de Defesa Civil é o mais citado pelos alunos nas redações e representado através dos desenhos. O símbolo da Defesa Civil e alguns conceitos sobre desastres naturais também são evidenciados nos trabalhos, o que nos faz perceber que os alunos leram as cartilhas relacionadas ao tema, que são entregues durante as aulas. Os principais desastres naturais ocorridos no município, como inundação e deslizamentos, são apontados de forma significativa nos desenhos. 
TABela IV - Critérios de percepção de risco no Clégio Sagrada Família.

TABLE IV - Features of risk perception at Sagrada Família School.

\begin{tabular}{|l|l|l|l|}
\hline \multicolumn{1}{|c|}{ Critérios } & Desenho & \multicolumn{1}{|c|}{ Redação } & \multicolumn{1}{|c|}{ Total } \\
\hline $\begin{array}{l}\text { Definição e conceito de DC e de desastres. Identificação de açães de proteção e segurança frente as } \\
\text { chuvas que geram deslizamento e enchente (8m) ou identificação do símbolollogo e atividades parceiras. }\end{array}$ & -- & 41 & 41 \\
\hline $\begin{array}{l}\text { Importância da solicitação de vistoria e avaliação de situações de risco ou acionamento para } \\
\text { emergência através do 199 - Defesa Civil. }\end{array}$ & 16 & 39 & 55 \\
\hline Lixo como causador de desastre & 08 & 25 & 33 \\
\hline Não construir em encostas ou morro & 46 & 28 & 72 \\
\hline Monitoramento das condições do tempo e nível do rio através do AlertaBlu & -- & 10 & 10 \\
\hline Cobertura vegetal em encostas/capim vetiver & 16 & 22 & 38 \\
\hline Não plantar bananeiras em encostas / Árvores grandes & 11 & 18 & 29 \\
\hline Abrigos & -- & 18 & 18 \\
\hline Co-responsabilidade nas ações de Defesa Civil (somos todos nós) & -- & 04 & 04 \\
\hline Importância do destino das águas pluviais e servidas & 05 & 07 & 13 \\
\hline Cuidado com o surgimento de rachaduras na residência & 06 & 07 & 13 \\
\hline Importância de calhas nos telhados & 04 & 04 & 08 \\
\hline
\end{tabular}

$\mathrm{Na}$ sequiência, percebe-se que os alunos atribuíram à Defesa Civil o papel de proteção, associando a importância dos munícipes solicitarem ao órgão a avaliação dos imóveis através do telefone 199 para garantir a segurança dos moradores, especialmente os que moram em áreas de risco.

O perigo de morar em encostas ou nos morros fica bastante evidente nos trabalhos, principalmente nos desenhos, onde a maioria divide a folha desenhando em uma parte uma situação segura e, na outra, situação de risco. Sobre este aspecto, no decorrer das aulas, ouvimos muitos depoimentos de alunos sobre membros da família que residem em morros, ou de vizinhos que construíram casas em locais impróprios para moradia. Referenciaram, ainda, a importância da presença de vegetação nos terrenos inclinados, especialmente do capim vetiver (fig. 5), citado durante a aula sobre percepção de risco, quando thes é passado um vídeo destacando esse capim como meio de contenção de encostas.

A questão do lixo não acondicionado/descartado corretamente é representada nas redações e desenhos como causadora de desastres - tema estudado na aula de percepção de risco, onde percebemos que os alunos associam o fato de que o lixo jogado no chão e o efeito da chuva entope os bueiros, potencializando a formação de enxurradas e alagamentos em vias públicas.

Nessa escola, a pedido da Direção, após o desenvolvimento do Programa, a Defesa Civil participou de uma exposição durante uma mostra cultural que durou uma semana, onde expôs os trabalhos desenvolvidos pelo alunos, permitindo que os familiares conheçam um pouco do trabalho de prevenção.

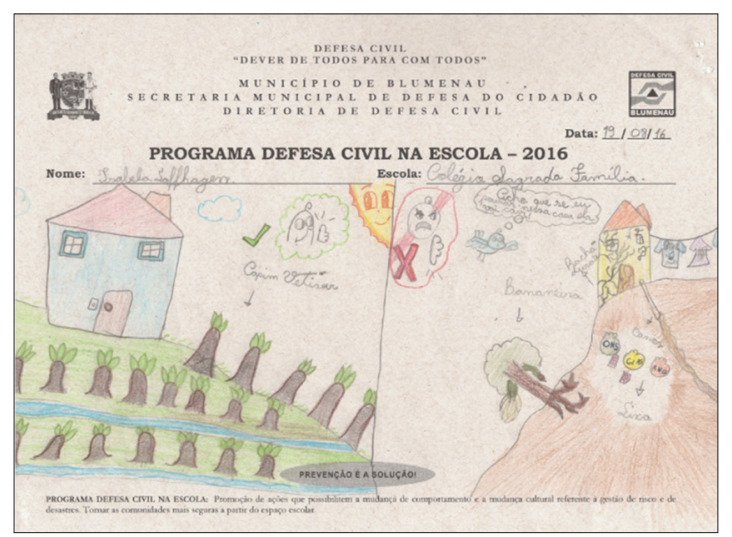

Fig. 5 - Desenho feito por uma aluna do $4^{\circ}$ ano do Colégio Sagrada Família (Fonte: Defesa Civil de Blumenau).

Fig. 5 - Picture by a $4^{\text {th }}$ grade student at Sagrada Família School (Source: Blumenau Civil Defense).

\section{Conclusão}

Através desses trabalhos, podemos perceber que o Programa de prevenção desenvolvido pela Defesa Civil contribui para a incorporação da percepção de risco nas crianças com relação aos desastres naturais. Com isso, vão desenvolvendo, de forma consciente, o seu papel na prevenção de desastres, tornando-se protagonistas da criação da cultura de prevenção nas comunidades, através da disseminação de práticas sustentáveis nos bairros. Como multiplicadores de informações, cria-se a possibilidade de os moradores identificarem os riscos e se prevenirem frente aos desastres naturais, contribuindo ainda para que a comunidade esteja cada vez mais segura e resiliente. 


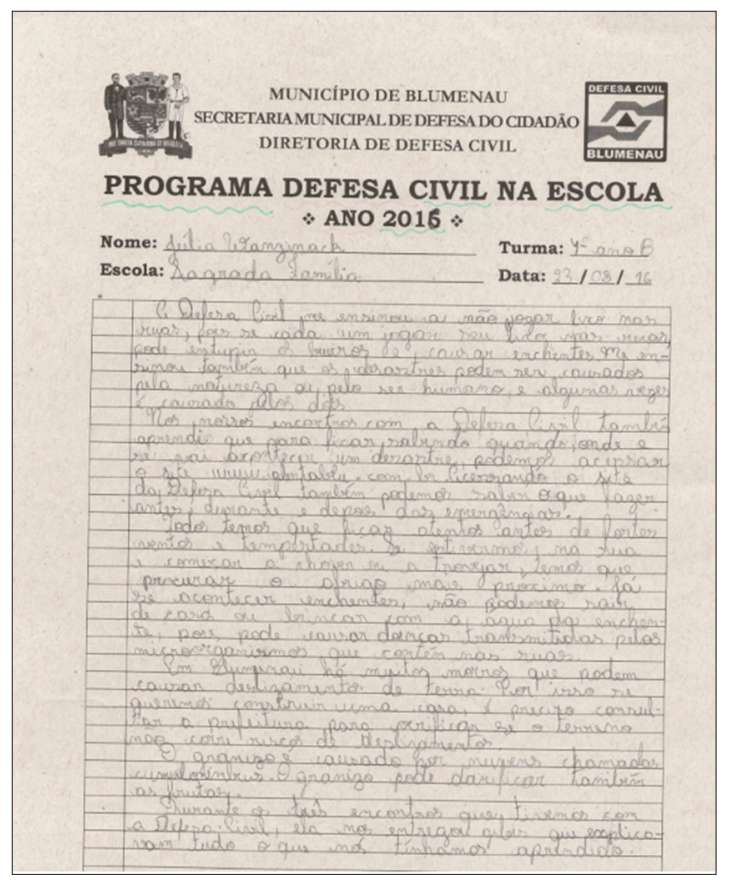

Fig. 6 - Redação feita por uma aluna do $4^{\circ}$ ano do Colégio Sagrada Família (Fonte: Defesa Civil de Blumenau).

Fig. 6 - Text written by a $4^{\text {th }}$ grade student at Sagrada Família School (Source: Blumenau Civil Defense).

De acordo com Marques et al. (2014, p. 15), "os frutos da educação ambiental tornam-se evidentes a partir do momento que os ensinamentos estão sendo passados $e$ praticado", não existindo público específico para esse tipo de ensinamento, podendo envolver desde crianças no contexto escolar ou trabalhadores em uma empresa.

Desta forma, constatamos através da análise do material e da observação nas aulas a importância da abordagem dessa temática no ambiente escolar, tendo em vista as ameaças as quais o município está exposto e a vulnerabilidade crescente da população. Através do Programa Defesa Civil na Escola, as crianças são empoderadas de conhecimento, o que possibilita a promoção de uma nova cultura de prevenção e com isso a redução dos riscos e dos impactos dos desastres.

\section{Bibliografia}

Alexander, D. (2011). Modelos de vulnerabilidade social a desastres. Revista Crítica de Ciências Sociais, (93), 09-29. . Acedido em 20 de janeiro de 2017 em http: //rccs.revues.org/113

Almeida, P. E. G. de (2015). A Política Nacional de Proteção e Defesa Civil: os desastres como problema político. $1^{\circ}$ Seminário Internacional de Ciência Política. Universidade Federal do Rio Grande do Sul, Porto Alegre, 2015. Acedido a 08 de abril de 2017 em https://www.ufrgs.br/sicp/ wp-content/uploads / 2015/09/ ALMEIDA-PaulaEm\%C3\%ADlia-G.-A-Pol\%C3\%ADtica-Nacional-deProte\%C3\%A7\%C3\%A3o-e-Defesa-Civil-desastrescomo-um-problema-pol\%C3\%ADtico.pdf.

BRASIL. CÂMARA DOS DEPUTADOS. COMISSÃO DE DEFESA DO CONSUMIDOR, MEIO AMBIENTE E MINORIAS (1995). Conferência das Nações Unidas sobre Meio Ambiente e Desenvolvimento: Agenda 21. Brasília: 1995.

Brasil. Lei $\mathrm{N}^{\circ}$ 12.608, de 10 de abril de 2012. Institui a Política Nacional de Proteção e Defesa Civil PNPDEC. Diário Oficial da União, Brasília: 2012.

Brasil. Lei $N^{\circ}$ 9.394, de 20 de dezembro de 1996. Estabelece as diretrizes e bases da educação nacional. Diário Oficial da União, Brasília:1996.

Brasil. Instrução Normativa n. ${ }^{\circ} 1$ de 24 de agosto de 2012. Ministério da Integração Nacional, Brasília: DOU de 24/08/2012.

Beck, Ulrich (2011) Sociedade de risco: rumo a uma outra modernidade. São Paulo: Editora 34, 2011.

CENTRE FOR RESEARCH ON THE EPIDEMIOLOGY OF DISASTERS (CRED), UNITED NATIONS INTERNATIONAL STRATEGY FOR DISASTER REDUCTION (UNISDR) (2015). O custo humano relacionado a desastres 1995 - 2015. Acedido a 24 de abril de 2017, em http: / /www.unisdr.org/we/inform/ publications. Acesso em: 15 de junho de 2016.

CEPED, U. (2012). Atlas brasileiro de desastres naturais 1991 a 2010: volume Brasil. Florianópolis, CEPED UFSC. Acedido a 12 de fevereiro de 2017, em http://150.162.127.14:8080/atlas/atlas2.html.

EIRD/ONU (ESTRATEGIA INTERNACIONAL PARA LA REDUCCIÓN DE DESASTRES, NACIONES UNIDAS) (2004). Vivir con el Riesgo - Informe mundial sobre iniciativas para la reducción de desastres. Secretaría Interinstitucional de la Estrategia Internacional para la Reducción de Desastres, Naciones Unidas (EIRD/ONU). 2004.

EMDAT. The International Disaster Database. Acedido a 15 de março de 2017 em: http://emdat.be/disaster_list/index.html

Douglas, M. e Wildavsky, A. (1983). Risk and Culture: an Essay on the Selection of Technological and Enviromental Dangers. Berkeley: University of California Press.

Marandola Junior, Ed. e Hogan, D. J.(2004). O risco em perspectiva: tendências e abordagens. Geosul. Florianópolis, Santa Catarina, Brasil, vol. 19, n. 38, p. 25 - 51. Acedido a 14 de fevereiro de 2017 em http: // journal.ufsc.br/index.php/geosul/article/view/13431

Marques, M. L. A. P., Silva, A. F., Araújo, J. E. Q., Queiroz, T. H. S., Almeida, I. D. A. e Marino, A. A. (2014). A educação ambiental na formação da consciência 
ecológica. Ciências exatas e tecnológicas, 1(1), 1118. Acedido a 10 de maio de 2017 em http://www. scielo.br/pdf/ep/v31n2/a07v31n2.pdf

Mattedi, M. A.. Butzke, I. C. (2001). A relação entre o social e o natural nas abordagens de hazards e de desastres. Ambiente e Sociedade. Ano IV. n. 09. 2001. 22p. Acedido a 05 de abril de 2017 em http: // www.scielo.br/pdf/asoc/n9/16877.pdf

Narváez, L., lavell, A. e Ortega, G. P. (2009). La gestión del riesgo de desastres: um enfoque basado em procesos. Secretaría General de la Comunidad. Andina, Lima, 2009.

Pozzobon, M. (2013). Análise da suscetibilidade a deslizamentos no município de Blumenau/SC: uma abordagem probalilística através da aplicação da técnica pesos de evidência (Tese de Doutorado). Universidade Federal do Paraná. Acedido a 28 de abril de 2017 em:

http://acervodigital.ufpr.br/handle/1884/37045

UNISDR. SENDAI FRAMEWORK FOR DISASTER RISK REDUCTION 2015-2030. UNITED NATIONS OFFICE FOR DISASTER RISK REDUCTION (2015). 25p. Acedido a 16 de fevereiro de 2017 em http://www.wcdrr.org/uploads/EN7.pdf

UNISDR. TERMINOLOGY ON DISASTER RISK REDUCTION. GENÉVA. UNITED NATIONS INTERNATIONAL STRATEGY FOR DISASTER REDUCTION (2009). Acedido a 14 de fevereiro de 2017, em http://www.unisdr.org/files/7817_ UNISDRTerminologyEnglish.pdf
UNISDR. HYOGO FRAMEWORK FOR ACTION 2005 - 2015-2030 (2014). Building the resilience of nations and communities to disasters. United Nations Office for Disaster Risk Reduction, 2005. 28p. Acedido a 10 de abril de 2017 em

ht tps: / / www. unisdr.org / we / inform / publications $/ 1037$

UNISDR. YOKOHAMA STRATEGY AND PLAN OF ACTION FOR A SAFER WORLD (1994). World Conferenceon Natural Disaster Reduction, 20p. Acedido a 10 de abril de 2017 em http://www.unisdr.org/files/8241_doc6841contenido1.pdf

Vendruscolo, S. e Kobiyama, M. (2007). Interfaces entre a Política Nacional de Recursos Hídricos e a Política Nacional de Defesa Civil, com relação aos desastres hidrológicos no Brasil. Universidade Federal de Santa Catarina, Florianópolis.

Vieira, R. e Furtado, S. M. de A. (2005). Percepções frente ao risco de deslizamento. Geosul, Florianópolis, v. 20, n. 40, p 55-75, jul./dez. 2005. Acedido a 28 de abril de 2017 em: https://periodicos.ufsc.br/index. $\mathrm{php/geosul/article/download/13236/12256}$

Vieira, R., Jansen, G. R. e Pozzobon, M. (2016). Redução de riscos de desastres naturais - A construção de políticas públicas em Blumenau-SC. Arquitextos. Acedido a 28 de abril de 2017 em: http://www.vitruvius.com.br/ revistas/read/arquitextos/16.188/5915 